DOI: $10.17805 / z p u .2016 .2 .28$

\title{
Социальное обслуживание как фактор повышения качества жизни пожилых людей (по материалам опроса экспертов)
}

\author{
О. А. ТюКИн \\ (МОСКОВСКИЙ ГУМАНИТАРНЫЙ УНИВЕРСИТЕТ)
}

В современных социально-экономических условиях жизнедеятельности пожилых людей наблюдается множество социальных рисков, негативно влияющих на качества их жизни и ведущих к возникновению проблем физиологического, психологического, материального и духовного характера. Пожилые люди нуждаются в активной социальной защите, ориентированной на минимизацию негативного влияния социальных рисков и улучшение качества их жизни. Статья посвящена изучению особенностей социального обслуживания как фактора повышения качества жизни пожилых людей.

Имеющиеся исследования и статистические данные показывают рост численности пожилых людей, относящихся к особой категории населения, подверженной социальным рискам и нуждающимся в организации эффективной системы социального обслуживания, разнообразной по формам и подходам к оказанию социальной помощи.

Автором зимой 2016 г. проведено эмпирическое исследование в г. Москве - опрос специалистов (21 эксперт), занятых в медико-социальной сфере и имеющих опыт взаимодействия с пожилыми людьми как субъектами социальных услуг. Объектом исследования стало качество жизни пожилых людей, подверженных социальным рискам, предметом исследования - их социальное обслуживание как фактор повышения качества жизни. Гипотеза исследования заключалась в том, что социальное обслуживание является важным фактором повышения качества жизни пожилых людей, однако лишь некоторые его формы (надомное и полустационарное) способны существенно повысить уровень качества жизни пожилых людей, подвергнутых социальным рискам. В результате проведенного исследования гипотеза была подтверждена. Экспертные оценки свидетельствуют, что социальное обслуживание рассматривается самими социальными работниками как важный фактор повышения качества жизни пожилых людей. Это обусловливает необходимость развития и совершенствования института социального обслуживания, в особенности таких его форм, как надомное и срочное социальное обслуживание.

Ключевые слова: пожилые люди; социальное обслуживание; социальные услуги; качество жизни; социальные риски; экспертное мнение

\section{BВЕАЕНИЕ}

П данным международной организации Help Age International, в XXI в. наблюдаются беспрецедентные глобальные демографические перемены, связанные с увеличением продолжительности жизни по всему миру. Старение населения занимает в них центральное место, поскольку к 2050 г. пожилые люди (в возрасте 60 лет или старше) будут составлять более одной пятой от общей численности населения мира $(22 \%)$ - 2,03 млрд человек против нынешних 809 млн (11\%) (Help Age International, Электронный ресурс). Вместе с тем до сих пор не существует какого-либо международного эталона, который бы демонстрировал, насколько благоприятны условия жизни для пожилых людей в тех или иных странах, так как сопоставимые на международном уровне данные об их положении по-прежнему ограничены (Федеральный закон № 442-Ф3: Электронный ресурс). Актуализируется вопрос оценки качества жизни пожилых людей, необходимой для обеспечения им нормальных условий жизнедеятельности в условиях экономической нестабильности, выработки подходов к социальной поддержке пожилых, в том числе за счет предоставления социальных услуг. 
Цель нашего исследования заключалась в получении и анализе мнения экспертов о социальном обслуживании как факторе повышения качества жизни пожилых людей.

\section{КАЧЕСТВО ЖИЗНИ ПОЖИАЫХ АЮАЕЙ: \\ ТЕОРИИ И ПОАХОАЫ К ИЗУЧЕНИЮ}

Междисциплинарный характер исследований условий жизнедеятельности человека породил у ученых значительное многообразие терминов и понятий, с помощью которых делалась попытка охарактеризовать жизненную среду обитания человека и уровень качества его жизни.

В 1964 г. понятие «качество жизни» было впервые использовано американским экономистом Аж. Гэлбрейтом в работе «Общество изобилия» (Galbraith, 1967). Позднее термин «качество жизни» использовался в работах представителей других научных направлений, что обусловило возникновение целого ряда теорий и концепций, характеризующих сущность и содержание качества жизни индивида. Можно выделить философский, экологический, экономический, психологический, медицинский подходы (Корнилова, 2012).

В контексте философской теории качество жизни рассматривается как «удовлетворенность личности уровнем реализации духовных, культурных потребностей, своей жизнедеятельностью в условиях социума» (Мазепина, 2014: 85). Экономический подход интерпретирует качество жизни как «отражение материального уровня благосостояния субъекта и как способность человека воспроизводить и увеличивать собственный материальный достаток» (Павлова, 1993: 42). В экологических теориях качество жизни понимается как "создание таких условий, при которых не только не нарушается состояние окружающей среды, но и сохраняются природные ресурсы, необходимые для существования будущих поколений» (Рященко, 2012: 113). Психологами качество жизни рассматривается как «субъективная удовлетворенность человека своей жизнью, что выражается в его оценке уровня и степени реализации своих потребностей» (Захарова, 2014: 142). В рамках медицинского подхода можно встретить понимание качества жизни как «восприятие индивидуумом его положения в жизни в контексте культуры и системы ценностей» (Адылханов, 2011: 79).

Представленные подходы к определению качества жизни учитывают различные аспекты жизнедеятельности индивида и не предполагают ограничений в плане пола, возраста и других социально-демографических характеристик индивида. Однако при применении данных подходов к категории пожилых людей необходимо учитывать их особенности. В соответствии с классификацией Всемирной организации здравоохранения (ВО3), сформированной в 1963 г., возраст 60-74 года признан пожилым 75-89 - старческим, а 90 лет и более - возрастом долгожителей (World Health Organization, 1986).

Специфика качества жизни пожилых людей во многом связана с социальными рисками, которые проявляются в их повседневной жизни и создают трудные жизненные ситуации. В общем ракурсе социальные риски могут носить экономический характер, социальный, политический, природный, техногенный и др. (Шарин, 2013: 118), однако в отношении пожилых людей принято выделять более конкретизированные социальные риски, свойственные данному возрасту, например бедность и материальное неблагополучие, ухудшение здоровья, риски преждевременной смерти, социальной изолированности, утраты родственных связей, деформации норм поведения, мошенничества (Корнилова, 2011). В научной литературе подчеркиваются такие основные 
проблемы жизнедеятельности пожилых людей, как неудовлетворенность своим нынешним социальным статусом, сложность трудоустройства, семейного благополучия, а также тяжелое восприятие физиологических изменений в организме (Перегуд, Королева, 2014: 71). Это вызывает не только необходимость учета рискологического положения пожилых людей в обществе, но и обусловливает необходимость непрерывной социальной поддержки пожилых, способной при грамотной организации повысить уровень качества жизни и снизить негативное влияние социальных рисков.

\section{СОЦИААЬНОЕ ОБСАУЖИВАНИЕ ПОЖИАЫХ АЮАЕЙ}

Согласно законодательству в сфере предоставления социальных услуг в широком смысле слова под социальным обслуживанием понимается деятельность по предоставлению социальных услуг гражданам. Под социальной услугой понимается «действие или действия в сфере социального обслуживания по оказанию постоянной, периодической, разовой помощи, в том числе срочной помощи, гражданину в целях улучшения условий его жизнедеятельности и (или) расширения его возможностей самостоятельно обеспечивать свои основные жизненные потребности» (Федеральный закон № 442: Электронный ресурс).

К социальным относятся социально-бытовые, социально-медицинские, социально-психологические, социально-педагогические, социально-трудовые, социальноправовые, коммуникативные и срочные социальные услуги (Симанов, 2008). Среди форм социального обслуживания выделяются три основные: социальное обслуживание на дому, социальное обслуживание в полустационарной форме, социальное обслуживание в стационарной форме (Михалев, 2009: 165).

Сегодня происходит развитие системы социальных служб. Цели, задачи, формы, методы социальной работы меняются в зависимости от социально-экономических факторов (стабильности или нестабильности). Происходит усиление государственного характера обеспечения основных гарантий социальной поддержки и обслуживания слабозащищенных категорий населения, пожилых, инвалидов (Янцен, 2015: 114).

При этом получение социальных услуг, сама процедура их получения представляет сложность для пожилого человека. Например, М. В. Корнилова отмечает, что услуги, оказываемые в отделении срочного социального обслуживания, можно получить бесплатно, однако многие одинокие пожилые граждане «группы риска» никогда не пользовались ими. Ведь зачастую даже для того, чтобы просто обратиться в отделение, написать заявление и представить документы, пожилому человеку не хватает сил и времени (Корнилова, 2015: 1843).

В настоящий момент важным является совершенствование института социального обслуживания и внедрение инновационных технологий предоставления социальных услуг. По мнению Т. К. Ауговской и А. В. Базаровой, к мерам повышения качества жизни пожилых людей за счет социального обслуживания относятся: стимулирование пожилых к росту их активности, самореализации; создание клубов по интересам; создание и внедрение инновационных форм социальной работы, таких как «университет третьего возраста», «социальный туризм», «приемная семья для престарелых», «тревожная кнопка», «бабушка и дедушка онлайн» (Ауговская, Базарова, 2014: 138).

Эффективный институт социального обслуживания пожилых людей способен противодействовать негативному влиянию социальных рисков при условии его системного совершенствования. Как пишет М. В. Корнилова, «функции института социальной защиты целесообразно дополнить защитой наиболее уязвимых категорий на- 
селения (пожилых людей) от типичных для них социальных рисков, усиливающихся в конкретные периоды, особенно при структурных социальных трансформациях» (Корнилова, 2015: 13). В исследовании М. И. Черепановой говорится о корреляции социального обслуживания с критическими социальными рисками, связанными с суицидом и эксклюзией пожилых людей (Черепанова, 2012: 428). Е. Н. Касаркина и Ю. А. Тузова утверждают изначальную объективную ориентацию института социального обслуживания на исключение социально-рисковых ситуаций в жизни пожилых людей (Касаркина, Тузова, 2013: 187).

В связи с этим возникает вопрос об эффективности отдельных форм и видов социальных услуг, соответствии их содержания потребностям пожилых людей, их способности к минимизации социальных рисков и повышению уровня качества жизни.

\section{ЭКСПЕРТНАЯ ОЦЕНКА СОЦИААЬНОГО ОБСАУЖИВАНИЯ}

КАК ФАКТОРА ПОВЫШЕНИЯ КАЧЕСТВА ЖИЗНИ ПОЖИАЫХ АЮАЕЙ

Аля оценки роли социального обслуживания пожилых людей в улучшении качества их жизни было организовано эмпирическое исследование путем использования метода экспертных оценок. Объектом исследования являлось качество жизни пожилых людей, подверженных социальным рискам, а предметом исследования стало социальное обслуживание как фактор повышения качества жизни пожилых людей. Цель исследования заключалась в проведении экспертной оценки возможностей социального обслуживания как фактора повышения качества жизни пожилых людей, подверженных социальным рискам.

Гипотеза исследования заключалась в предположении о том, что социальное обслуживание действительно является важным фактором повышения качества жизни пожилых людей, однако лишь некоторые его формы (надомное и полустационарное) способны существенно повысить уровень качества жизни пожилых людей, подвергнутых социальным рискам.

Руководителем исследовательской группы выступил автор данной статьи. Исследование проводилось в г. Москве в январе - феврале 2016 г.

Респондентами эмпирического исследования стал 21 әксперт (16 женщин и 5 мужчин в возрасте 27-56 лет) - специалисты из центров социального обслуживания и учреждений разного административно-территориального и ведомственного подчинения. Главными критериями при отборе экспертов являлись следующие: 1) принадлежность экспертов к научному сообществу; 2) работа в штате профильных учреждений по социальной защите, занятых предоставлением социальных услуг пожилым людям на дому; 3) большой опыт в работе с пожилыми людьми.

Рассмотрим результаты проведенного исследования.

Прежде чем подойти к вопросу о роли социального обслуживания как фактора повышения качества жизни пожилых людей, мы попросили экспертов оценить значимость тех или иных показателей качества жизни.

Среди объективных показателей эксперты посчитали наиболее значимыми следующие: отсутствие серьезных проблем со здоровьем $(24 \%)$ возможность материального обеспечения (21\%), материальный достаток (19\%), свободный доступ к медицинским услугам и их получению (16\%), наличие хороших жилищных условий $(14 \%)$, наличие постоянного социального взаимодействия $(6 \%)$.

К основным субъективным показателям качества жизни пожилых людей экспертами были отнесены: удовлетворенность своим здоровьем (27\%), удовлетворенность ма- 
териальным достатком (24\%), удовлетворенность жизненными условиями (19\%), удовлетворенность получаемым медицинским обслуживанием (16\%), удовлетворенность общения с родственниками, друзьями (14\%). Так, по мнению экспертов, качество жизни пожилых людей определяется прежде всего уровнем их здоровья, материального достатка и доступом к получению медицинских услуг, однако подчеркивается и значимость взаимодействия пожилых людей с близкими родственниками, Арузьями.

Аалее было установлено экспертное мнение в отношении социального обслуживания. На вопрос: «Могут ли государственные социальные услуги обеспечить должный уровень качества жизни пожилых людей?» - большинство экспертов ответило «скорее да, чем нет» (48\%). Вариант «точно да» выбрали 24\% респондентов. Вариант «скорее нет, чем да» выбрали 20\% экспертов, и вариант «нет»-8\%. Так, более половины экспертов склоняются к мнению о том, что социальные услуги действительно способны обеспечивать должный уровень качества жизни пожилых людей.

В ходе исследования экспертам было предложено ранжировать формы и виды социальных услуг по степени их значимости в обеспечении должного уровня качества жизни пожилых людей. На первом месте среди форм социальных услуг оказалось надомное социальное обслуживание (42\%), на втором - полустационарные социальные услуги (38\%), на третьем - стационарные социальные услуги (20\%). В ходе ранжирования социальных услуг по видам было установлено, что наиболее значимыми стали социально-медицинские услуги (33\%), на втором месте - социально-психологические $(30 \%)$, на третьем - социально-бытовые (26\%). Полученные результаты свидетельствуют о том, что для повышения уровня качества жизни пожилых людей эксперты рекомендуют активно реализовывать надомные и полустационарные социальные услуги, поскольку иные формы социальных услуг в меньшей степени способны противостоять социальным рискам, негативно влияющим на жизнедеятельность пожилого человека.

Также экспертам был задан вопрос о необходимости создания специального критериального аппарата для оценки качества жизни пожилых людей на уровне регионов. 32\% экспертов ответили, что такой критериальный аппарат необходим для формирования эффективной государственной политики социальной защиты населения; вариант «скорей необходим, чем нет» выбрали 26\% экспертов. Мы считаем, что создание специального критериального аппарата для оценки качества жизни пожилых позволит более продуктивно систематизировать и анализировать информацию о результатах влияния социального обслуживания на качество жизни пожилых людей.

Ответы на вопрос о том, позволит ли ориентация социального обслуживания пожилых людей на концепцию качества жизни снизить вероятность возникновения социальных рисков, распределились следующим образом: «да»-42\%, «скорей да, чем нет»-32\%, «скорей нет, чем да»-16\%, «нет»-10\%.

На заключительном этапе эмпирического исследования экспертам были заданы вопросы, характеризующие их опыт предотвращения социальных рисков пожилых людей средствами социального обслуживания. 27\% экспертов утверждают, что в практике их профессиональной деятельности встречались случаи предотвращения социальных рисков пожилых людей в результате оказания им социальных услуг. При общении с экспертами данный вопрос был раскрыт более подробно. Обращаясь к своему опыту, эксперты объяснили, что предотвращение социальных рисков пожилых заключалась в своевременном оказании социальных услуг того вида, который соот- 
ветствовал наблюдаемым социальным рискам: нуждающимся в медико-социальной помощи была оказана поддержка по получению льгот на лекарственные средства; для тех, кто характеризовался признаками десоциализации, сотрудники медико-социальных служб организовали посещение специальных клубов по интересам. В заключение респондентам был задан вопрос о том, каков приблизительный процент случаев оказания социальных услуг пожилым людям, в результате которых были предотвращены социальные риски. $65 \%$ экспертов утверждают, что предотвращение социальных рисков наблюдается в 35-50\% случаев, 35\% - в 15-35\% случаев. При этом эксперты подчеркнули, что особенно важна профилактика социальных рисков посредством предоставления социальных услуг пожилым людям. Результативность профилактики, согласно экспертному мнению, определяется своевременностью социальных услуг и возможностью системной и оперативной диагностики социальных рисков.

\section{ЗАКАЮЧЕНИЕ}

Проведенное исследование позволило сформулировать следующие выводы. Качество жизни пожилых людей в современном российском обществе находится под влиянием социальных рисков, связанных со здоровьем, материальным положением, доступностью медико-социальных услуг, условиями проживания и др. Аля предотвращения социальных рисков, минимизации их негативного влияния и повышения уровня качества жизни пожилых людей необходимо активное развитие института социального обслуживания.

Проведенное эмпирическое исследование было направлено на экспертную оценку социального обслуживания как фактора повышения качества жизни пожилых людей. Результаты исследования свидетельствуют о том, что социальное обслуживание действительно играет важную роль в обеспечении надлежащего уровня качества жизни пожилых, причем особо выделяется надомная форма социального обслуживания, способная максимально приблизить социальные услуги к месту проживания пожилого человека, реализовать принцип адресности и доступности социальной помощи.

\section{СПИСОК АИТЕРАТУРЫ}

Федеральный закон от 28.12.2013 № 442-Ф3 (ред. от 21.07.2014) «Об основах социального обслуживания граждан в Российской Федерации» [Электронный ресурс]// Консультант Плюс. URL: http://www.consultant.ru/document/cons_doc_LAW_166044/ (дата обращения: 13.03.2016).

Адылханов, Т. А. (2011) Современные методы оценки качества жизни в онкологии // Наука и здравоохранение. № 1. С. 79-83.

Захарова, А. Н. (2014) Междисциплинарная проблема качества жизни в контексте современных научных исследований // Вестн. психиатрии и психологии Чувашии. № 10. С. 141-161.

Касаркина, Е. Н., Тузова Ю. А. (2013) Система социальной защиты пожилых людей в России // Актуальные проблемы современной науки в XXI веке : материалы Междунар. науч.практ. конф. / отв. ред. Ш. М. Гимбатов. Махачкала : ООО «Апробация». 190 с. С. 185-187.

Корнилова, М. В. (2011) Качество жизни и социальные риски пожилых людей // Современные исследования социальных проблем. № 3. Т. 7. С. 13-17.

Корнилова, М. В. (2012) Институт социальной защиты населения в условиях усиления социальных рисков (на примере социального обслуживания пожилых граждан г. Москвы) : автореф. дис. ... канд. социол. наук, Москва. 22 с.

Корнилова, М. В. (2015) Срочное социальное обслуживание и социальная защита пожилых москвичей группы «риска» // Россия в современном мире: взгляд социолога : материалы науч.практ. конф. / отв. ред. Ю. В. Асочаков. СПб. : ООО «Скифия-Принт». 2248 с. С. 1842-1844. 
Ауговская, Т. К., Базарова, А. В. (2014) Социальное благополучие пожилых и престарелых людей: роль инноваций в социальном обслуживании // Формы и методы социальной работы в различных сферах жизнедеятельности : материалы III Междунар. науч.-практ. конф. / отв. ред. Б. Б. Танганов. Улан-УАэ : Восточно-Сибирский гос. ун-т технологий и управления. 257 с. C. $138-139$.

Мазепина, О. Ю. (2014) Проблемы измерения уровня и качества жизни населения // Проблемы развития территории. № 6. С. 83-89.

Михалев, И. В. (2009) Развитие организационных форм социального обслуживания населения России // Сервис в России и за рубежом. № 1. С. 164-169.

Павлова, $\Lambda$. Е. (1993) Обзор зарубежной литературы по проблемам качества жизни и качества населения // Аемография и социология / отв. ред. И. А. Алибастова. М. : Ин-т соц.-эконом. проблем народонаселения. 192 с. С. 112-119.

Перегуд, С. А., Королева, Э. В. (2014) Социальное обслуживание граждан пожилого возраста и инвалидов // Инновационное развитие современной науки : сб. ст. Междунар. науч.практ. конф. / отв. ред. А. А. Сукиасян. Уфа : ООО «Омега Сайнс». 182 с. С. 70-73.

Рященко, С. В. (2012) Качество жизни в антропоэкологическом измерении // География и природные ресурсы. № 3. С. 115-119.

Симанов, Р. Е. (2008) Становление системы социального обслуживания в России // Система ценностей современного общества. № 1. С. 197-200.

Черепанова, М. И. (2012) Социальная эксклюзия как один из факторов суицидальных рисков среди лиц пожилого и старческого возраста // Мир науки, культуры, образования. № 6. C. $425-429$.

Шарин, В. И. (2013) Социальные риски как угрозы социальному положению и защита от них // Известия Уральск. гос. эконом. ун-та. № 6. С. 118-124.

Янцен, М. А. (2015) Социальное обслуживание пожилых людей как социальный процесс // Wschodnioeuropejskie czasopismo naukowe (East European Scientific Journal). № 2. C. 114-118.

HelpAgeInternational: Индекс качества жизни пожилых людей в странах мира в 2013 г. [Электронный ресурс]// Центр гуманитарных технологий. URL: http:/gtmarket.ru/ratings/globalage-wath-index/info (дата обращения: 13.03.2016).

Galbraith, J. K. (1967) The New Industry State. Boston, MA : Houghton Mifflin. 612 p.

World Health Organization. Cancer pain relief (1986). Geneva : WHO. 26 p.

Аата поступления: 20.03.2016 г.

SOCIAL CARE AS A FACTOR IN IMPROVING THE QUALITY OF LIFE OF THE ELDERLY

(ON THE BASIS OF EXPERT SURVEY)

O. A. TYUKIN

(MOSCOW UNIVERSITY FOR THE HUMANITIES)

The current social and economic situation is a source of many social risks for the elderly. There risks have a negative impact on their quality of life and give rise to a number of physiological, psychological, material and spiritual issues. The elderly stand in need of proactive social care aimed at minimizing the negative impact of social risks and at improving quality of living. This article examines social services as a factor of such an improvement.

The available statistical data and research show the rise in the numbers of the elderly who experience social risks and need an efficient system of social services which would make use of a variety of forms and methods of social aid.

In winter 2016 we conducted an empirical study in Moscow in the form of an expert survey. All of the 21 respondent experts worked in the medical and social sphere and had had experience of working with the elderly as recipients of social services. The study focused at the quality of life of the elderly who are susceptible of social risks and at the social services they receive as a factor of improving the quality of living. Our hypothesis was that while social care is generally an important factor of 
improving the quality of life, only some of its forms (such as in-home aid or daycare) can significantly raise the quality of life of the elderly who run social risks. The survey fully confirmed our hypothesis. As it becomes clear from the expert assessments, the social workers themselves view social care as an important factor of improving the quality of living of the elderly. This emphasizes the need to develop and improve the institute of social care, especially emergency and in-home social aid.

Keywords: elderly; social care; social services; quality of life; social risks; expert opinion

\section{REFERENCES}

Federal'nyi zakon ot 28.12.2013 № 442-FZ (red. ot 21.07.2014) «Ob osnovakh sotsial'nogo obsluzhivaniia grazhdan v Rossiiskoi Federatsii» [Federal Law No. 442-FZ "On the foundations of social services in Russian Federation" of 28.12.2003 (as amended on 21.07.2014)]. Konsul' tant Plius [online] Available at: http://www.consultant.ru/document/cons_doc_LAW_166044/ (access date: 13.03.2016). (In Russ.).

Adylkhanov, T. A. (2011) Sovremennye metody otsenki kachestva zhizni v onkologii [Contemporary methodologies of assessing quality of life in oncology]. Nauka $i$ dravookbranenie, no. 1, pp. 79-83. (In Russ.).

Zakharova, A. N. (2014) Mezhdistsiplinarnaia problema kachestva zhizni v kontekste sovremennykh nauchnykh issledovanii [The interdisciplinary issue of the quality of life in the context of contemporary research]. Vestnik psikbiatrii i psikbologii Chuvashii, no. 10, pp. 141-161. (In Russ.).

Kasarkina, E. N. and Tuzova Iu. A. (2013) Sistema sotsial'noi zashchity pozhilykh liudei v Rossii [Providing social care to the elderly in Russia]. In: Aktual'nye problemy sovremennoi nauki $v$ XXI veke : materialy Mezhdunar. nauch.-prakt. konf. [Topical issues of contemporary science in the $21^{\text {st }}$ century: Proceedings of an international conference], ed. Sh. M. Gimbatov. Makhachkala, OOO Aprobatsiia Publ. 190 p. Pp. 185-187. (In Russ.).

Kornilova, M. V. (2011) Kachestvo zhizni i sotsial'nye riski pozhilykh liudei [Quality of life and social risks for the elderly]. Sovremennye issledovaniia sotsial' nykb problem, no. 3, vol. 7, pp. 13-17.

Kornilova, M. V. (2012) Institut sotsial'noi zasbchity naseleniia $v$ usloviiakb usileniia sotsial'nykb riskov (na primere sotsial'nogo obsluzbivaniia pozbilykb grazhdan g. Moskvy) [The institute of social care under increasing social risks (the case of providing social services for the elderly in Moscow)] : abstract of the dissertation ... Candidate of Sociology, Moscow. 22 p. (In Russ.).

Kornilova, M. V. (2015) Srochnoe sotsial'noe obsluzhivanie i sotsial'naia zashchita pozhilykh moskvichei gruppy «riska» [Emergency social services and social care for the elderly Muscovites belonging to the risk group]. In: Rossiia v sovremennom mire: vzgliad sotsiologa : materialy nauch.-prakt. konf. [Russia in the contemporary world: A sociologist's view: Proceedings of a research conference], ed. Yu. V. Asochakov. Saint Petersburg, OOO Skifiia-Print Publ. 2248 p. Pp. 1842-1844. (In Russ.).

Lugovskaia, T. K. and Bazarova, A. V. (2014) Sotsial'noe blagopoluchie pozhilykh i prestarelykh liudei: rol' innovatsii v sotsial'nom obsluzhivanii [Social wellbeing of the elderly: the role of innovation in social services]. In: Formy $i$ metody sotsial' noi raboty $v$ razlichnykb sferakb zhiznedeiatel' nosti : materialy III Mezhdunar. nauch.-prakt. konf. [Forms and methods of social work in various spheres of life: Proceedings of 3rd international research conference], ed. B. B. Tanganov. Ulan-Ude, East Siberian State Universities of Engineering and Management. Pp. 138-139. (In Russ.).

Mazepina, O. Yu. (2014) Problemy izmereniia urovnia i kachestva zhizni naseleniia [Issues of measuring the standard and quality of life]. Problemy razvitiia territorii, no. 6, pp. 83-89. (In Russ.).

Mikhalev, I. V. (2009) Razvitie organizatsionnykh form sotsial'nogo obsluzhivaniia naseleniia Rossii [The development of organizational forms of providing social services in Russia]. Servis $v$ Rossii i za rubezhom, no. 1, pp. 164-169. (In Russ.).

Pavlova, L. E. (1993) Obzor zarubezhnoi literatury po problemam kachestva zhizni i kachestva naseleniia [Foreign literature on quality of life and population quality]. In: Demografiia $i$ sotsiologiia [Demography and sociology], ed. I. A. Alibastova. Moscow, Institute for Social and Economic Issues of the Population. 192 p. Pp. 112-119. (In Russ.).

Peregud, S. A. and Koroleva, E. V. (2014) Sotsial'noe obsluzhivanie grazhdan pozhilogo vozrasta $\mathrm{i}$ invalidov [Providing social services to the elderly and the disabled]. In: Innovatsionnoe razvitie so- 
vremennoi nauki : sb. st. Mezhdunar. nauch.-prakt. konf. [Innovative development in contemporary science: A collection of articles], ed. A. A. Sukiasian. Ufa, OOO Omega Sains Publ. 182 p. Pp. 70-73. (In Russ.).

Riashchenko, S. V. (2012) Kachestvo zhizni v antropoekologicheskom izmerenii [Quality of life in an anthopoenvironmental dimension]. Geografiia i prirodnye resursy, no. 3, pp. 115-119. (In Russ.).

Simanov, R. E. (2008) Stanovlenie sistemy sotsial'nogo obsluzhivaniia v Rossii [The rise of the system of social care in Russia]. Sistema tsennostei sovremennogo obshchestva, no. 1, pp. 197-200. (In Russ.).

Cherepanova, M. I. (2012) Sotsial'naia ekskliuziia kak odin iz faktorov suitsidal'nykh riskov sredi lits pozhilogo i starcheskogo vozrasta [Social exclusion as a suicide risk factor among the elderly]. Mir nauki, kul'tury, obrazovaniia, no. 6, pp. 425-429. (In Russ.).

Help Age International: Indeks kachestva zhizni pozhilyh ljudej v stranah mira v 2013 g. [Help Agay international: Index of the quality of life of older people in the world in 2013]. Tsentr gumanitarnykb tekbnologii [online] Available at: http://gtmarket.ru/ratings/global-age-wath-index/info (date of access: 13.02.2015). (In Russ).

Sharin, V. I. (2013) Sotsial'nye riski kak ugrozy sotsial'nomu polozheniiu i zashchita ot nikh [Social risks as threats to social status and protection from them]. Izvestiia Ural'skogo gosudarstvennogo ekonomicheskogo universiteta, no. 6, pp. 118-124.

Iantsen, M. A. (2015) Sotsial'noe obsluzhivanie pozhilykh liudei kak sotsial'nyi protsess [Providing social services to the elderly as a social process] Wschodnioeuropejskie czasopismo naukowe (East European Scientific Journal), no. 2, pp. 114-118. (In Russ). (In Russ.)

Galbraith, J. K. (1967) The New Industry State. Boston, MA: Houghton Mifflin. 612 p.

World Health Organization. Cancer pain relief (1986). Geneva: WHO. 26 p.

Submission date: 20.03 .2016

Тюкин Олег Анатольевич - аспирант кафедры социологии Московского гуманитарного университета, специалист выездной бригады Станции скорой и неотложной медицинской помощи им. А. С. Пучкова г. Москвы, член Российского общества социологов. Адрес: 111395 , Россия, г. Москва, ул. Юности, д. 5. Тел.: +7 (499) 374-60-21. Эл. адрес: Le_go@mail.ru. Научный руководитель - А-р социол. наук, проф. М. Г. Солнышкина.

Tyukin Oleg Anatolievich, Postgraduate student, Department of sociology, Moscow University for the Humanities; Specialist, A.S. Puchkov Station of ambulance and emergency medical care, Moscow; Member, Russian Society of Sociologists. Postal address: 5 Yunosti St., Moscow, Russian Federation, 111395. Tel.: +7 (499) 374-60-21. E-mail: Le_go@mail.ru. Research adviser — Professor, Doctor of Sociology M.G. Solnyshkina. 